\title{
Behind-the-Meter Solar Accounting in Renewable Portfolio Standards
}

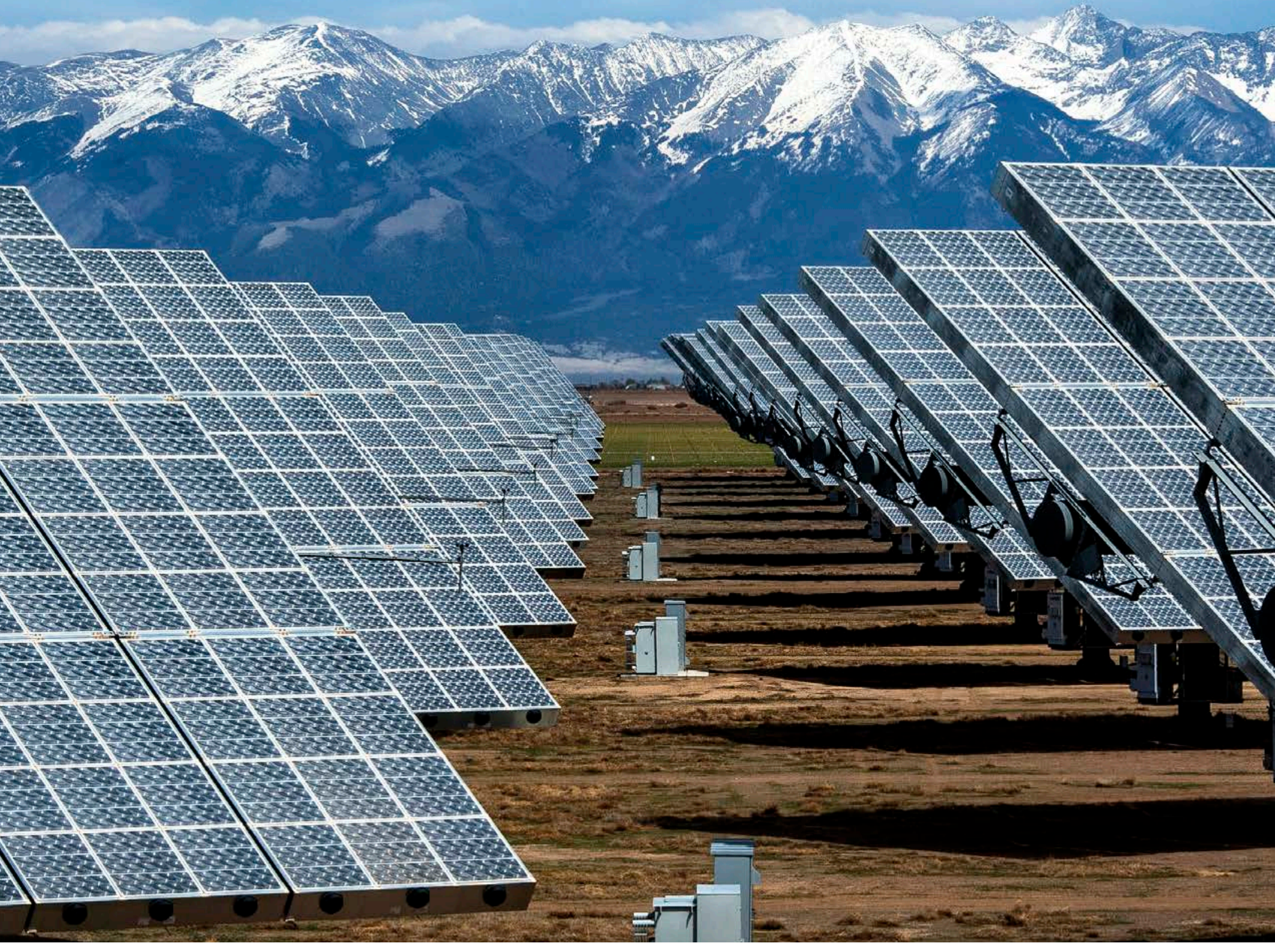

Managing Solar Photovoltaic Integration in the Western United States 


\title{
Behind-the-Meter Solar Accounting in Renewable Portfolio Standards
}

\author{
Pieter Gagnon, Elaine Hale, and Brady Cowiestoll \\ National Renewable Energy Laboratory
}

\author{
Suggested Citation \\ Gagnon, Pieter, Elaine Hale, and Brady Cowiestoll. 2020. Behind-the-Meter Solar \\ Accounting in Renewable Portfolio Standards. Golden, CO: National Renewable Energy \\ Laboratory. NREL/TP-6A20-72473. https://www.nrel.gov/docs/fy21osti/72473.pdf.
}




\section{NOTICE}

This work was authored in part by the National Renewable Energy Laboratory, operated by Alliance for Sustainable Energy, LLC, for the U.S. Department of Energy (DOE) under Contract No. DE-AC36-08GO28308. Research commissioned by the Western Interstate Energy Board (WIEB). Funding provided by the DOE Office of Energy Efficiency and Renewable Energy Solar Energy Technologies Office. The views expressed herein do not necessarily represent the views of the DOE or the U.S. Government.

This report is available at no cost from the National Renewable Energy Laboratory (NREL) at www.nrel.gov/publications.

U.S. Department of Energy (DOE) reports produced after 1991 and a growing number of pre-1991 documents are available free via www.OSTI.gov.

Cover photo by Dennis Schroeder: NREL 30542.

NREL prints on paper that contains recycled content. 


\section{Abstract}

If a behind-the-meter solar photovoltaic (BTM PV) system is adopted, how does that influence the total amount of renewable electricity in its state in the long run (i.e., after the existence of the generator is reflected in the relevant utility's generation mix)? Would we expect the total amount of renewable generation to increase on a 1:1 basis with the BTM PV's generation? Or could it be something more, or something less? We show in this paper that the answer can depend on two key elements of how BTM PV is accounted for in a state's renewable portfolio standard (RPS): (1) whether renewable energy certificates (RECs) from BTM PV can be used for RPS compliance, and (2) whether load served by generation from BTM PV counts as load covered by the RPS. These two elements combine into four possible accounting options, and we characterize the implications of each under the simplifying assumptions that the RPS is binding and the BTM PV RECs are used for compliance when allowed. For example, if load served by BTM PV generation counts toward the RPS load and BTM PV RECs cannot be used for compliance, the presence of BTM does not change the amount of RECs that the utility is required to retire, and yet additional RECs will be retired by the BTM PV owner - therefore, the total amount of renewable generation would increase on a 1:1 basis with the BTM PV generation. In contrast, under a common RPS design in which BTM PV RECs can be used for compliance and the load served by BTM PV generation is not covered by the RPS, the presence of BTM PV and transfer of RECs for compliance can actually decrease the total amount of renewable generation in the state, relative to a situation in which there is no BTM PV. 


\section{Preface}

This report is one in a series examining potential challenges related to planning future power systems with higher solar photovoltaic (PV) penetrations. In recent years, numerous renewable integration studies have examined power system operations with various wind and solar penetrations and have found it feasible to balance supply and demand. There are also examples of power systems currently operating with significant penetrations of wind or solar power in the literature. This series of reports focuses on solar PV generation specifically and delves deeper into potential integration issues that may not be so challenging at moderate penetrations but could be of more import at higher PV penetrations.

The series uses the western U.S. power system for these investigations because it is a region the authors and their colleagues have already extensively studied. We are therefore well-suited to analyze even higher PV penetrations and then examine the results in multiple models to determine whether our current approaches are missing key details that only emerge at higher PV penetrations. We also examine three regions in the western United States with significantly different existing power systems and connections to neighboring regions; this provides a more balanced picture as to how high PV penetration systems might operate in different contexts and what the resulting issues, if any, might be.

The four publications in this series are listed and described in Table ES-1.

Table ES-1. Reports in the Managing Solar Photovoltaic Integration in the Western United States Series

\begin{tabular}{|l|l|}
\hline Title & Description \\
\hline $\begin{array}{l}\text { Managing Solar Photovoltaic Integration in the } \\
\text { Festern United States: Power System }\end{array}$ & $\begin{array}{l}\text { Assessment of net load ramping needs and what } \\
\text { resources are available to provide upward and } \\
\text { downward ramping at different timescales }\end{array}$ \\
\hline $\begin{array}{l}\text { Managing Solar Photovoltaic Integration in the } \\
\text { Western United States: Resource Adequacy }\end{array}$ & $\begin{array}{l}\text { Probabilistic resource adequacy assessment of high } \\
\text { PV penetration scenarios and comparison to planning } \\
\text { reserve margin approaches using capacity credit } \\
\text { approximation methods }\end{array}$ \\
\hline $\begin{array}{l}\text { Behind-the-meter Solar Accounting in } \\
\text { Renewable Portfolio Standards }\end{array}$ & $\begin{array}{l}\text { An exploration of how two renewable portfolio } \\
\text { standard design elements can influence the } \\
\text { interaction of behind-the-meter PV and total } \\
\text { renewable generation }\end{array}$ \\
\hline $\begin{array}{l}\text { Managing Solar Photovoltaic Integration in the } \\
\text { Western United States Appendix: Reference } \\
\text { and High Solar Photovoltaic Scenarios for } \\
\text { Three Regions }\end{array}$ & $\begin{array}{l}\text { Resource Planning Model (RPM) inputs, scenario } \\
\text { framework, and results for RPM-AZ, RPM-CO, and } \\
\text { RPM-OR; two of the papers in the series use these } \\
\text { scenarios as their starting point for analysis }\end{array}$ \\
\hline
\end{tabular}

This report is listed in bold type.

This report series was commissioned by the Western Interstate Energy Board (WIEB) as part of the Enhanced Distributed Solar Photovoltaic Deployment via Barrier Mitigation or Removal in the Western Interconnection project funded by the U.S. Department of Energy (DOE) Office of 
Energy Efficiency and Renewable Energy (EERE) Solar Energy Technologies Office (SETO). ${ }^{1}$ For more information, including links to other reports, see

https://www.westernenergyboard.org/western-interstate-energy-board/barrier-mitigation-toenhanced-distributed-solar-photovoltaic/.

\footnotetext{
${ }^{1}$ An additional work was published as a journal article: Kenyon, Rick Wallace, Matthew Bossart, Marija Marković, Kate Doubleday, Reiko Matsuda-Dunn, Stefania Mitova, Simon A. Julien, Elaine T. Hale, and Bri-Mathias Hodge. 2020. "Stability and Control of Power Systems with High Penetrations of Inverter-Based Resources: An Accessible Review of Current Knowledge and Open Questions." Solar Energy, Special Issue on Grid Integration, 210: 149-68. https://doi.org/10.1016/j.solener.2020.05.053.
} 


\section{Acknowledgments}

This work was supported by the U.S. Department of Energy (DOE) Office of Energy Efficiency and Renewable Energy (EERE) Solar Energy Technologies Office (SETO), as part of a wider project led by the Western Interstate Energy Board (WIEB). The authors would specifically like to thank Michele Boyd (DOE) for supporting this and other SEEDS2-SES ${ }^{2}$ projects, and Maury Galbraith, David Manning, Richard McAllister, and Holly Taylor (WIEB) for partnering with us on the Enhanced Distributed Solar Photovoltaic Deployment via Barrier Mitigation or Removal in the Western Interconnection project. We would also like to thank Lori Bird and David Hurlbut of the National Renewable Energy Laboratory (NREL) for their project management support and leadership.

The idea for this series of reports was developed with input from several of our colleagues at NREL and the project's technical advisory committee. Lori Bird, Kara Clark, Michael Coddington, Paul Denholm, Barry Mather, Michael Milligan, Bryan Palmintier, and Mark Ruth (NREL) provided input to an initial screening analysis of PV reliability barriers. The barriers screening analysis was then reviewed with the committee, as was a research plan developed in response to the screening results. We would like to thank committee members for their participation in those processes as well as for the review and guidance they provided throughout the execution of the research. The results and findings in this report and the broader project do not necessarily reflect their opinions or the opinions of their institutions. The committee is composed of the following individuals:

- Jim Baak, Vote Solar

- Guru Belavadi, Arizona Corporation Commission

- Ken Bolton, Western Electricity Coordinating Council

- Enoch Davies, Western Electricity Coordinating Council

- Tom Flynn, California Energy Commission

- Jennifer Gardner, Western Resource Advocates

- Daniel Haughton, Arizona Public Service Electric Company

- Carl Linvill, Regulatory Assistance Project

- Toby Little, Arizona Corporation Commission

- Clyde Loutan, California Independent System Operator

- Louise Nutter, Federal Energy Regulatory Commission

- Vijay Satyal, Western Electricity Coordinating Council

- Courtney Smith, California Energy Commission

The authors would like to thank Richard McAllister, Michele Boyd, David Hurlbut, Jenny Heeter, and Dan Steinberg for helpful review comments and Mike Meshek for his diligence in editing.

\footnotetext{
${ }^{2}$ SEEDS2-SES is the Solar Energy Evolution and Diffusion Studies 2 - State Energy Strategies program. For information about the program, see https:/www.energy.gov/eere/solar/solar-energy-evolution-and-diffusion-studies2-state-energy-strategies-seeds2-ses.
} 


\section{List of Acronyms}

BTM behind-the-meter

DOE

U.S. Department of Energy

EERE

PV

Energy Efficiency and Renewable Energy

photovoltaic

NREL

REC

RPS

SEEDS2-SES

SETO

WIEB

National Renewable Energy Laboratory

renewable energy certificate

renewable portfolio standard

Solar Energy Evolution and Diffusion Studies 2 - State Energy Strategies Solar Energy Technologies Office

Western Interstate Energy Board 


\section{Table of Contents}

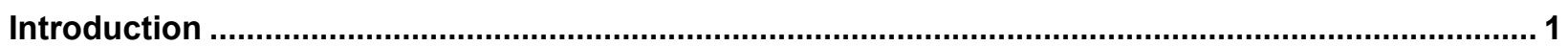

How BTM PV Accounting in an RPS Can Affect Renewable Generation Requirements .................... 3

BTM PV and RPS Interactions Under a Range of RPS Goals ..................................................... 8

General Equations for Total Renewable Generation Under Different RPS Accounting Options ....... 7

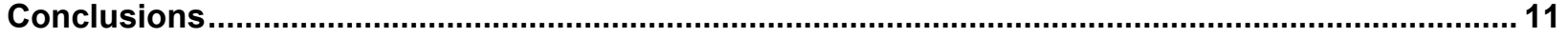

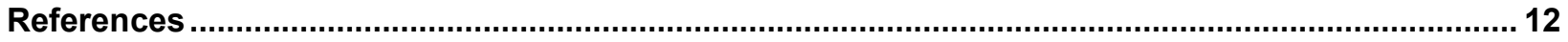

Appendix: RPS Literature and Resources............................................................................. 13 


\section{List of Figures}

Figure 1. Renewable Generation as a Percentage of Total Electricity Consumption for a Range of RPS

Goals, Under Four RPS Accounting Options

\section{List of Tables}

Table ES-1. Reports in the Managing Solar Photovoltaic Integration in the Western United States Series

Table 1. Renewable Energy Generation in a Hypothetical State Under Four Accounting Options for Behind-the-Meter PV in Renewable Portfolio Standards ...................................................... 5

Table 2. Total Amount of Renewable Generation in a Hypothetical State Under Various RPS Accounting Options......

Table 3. Marginal Influence that an additional kWh of Behind-the-meter PV has on the Total Renewable Generation Under Various Accounting Options, in a Hypothetical State with a 30\% RPS .... 6

Table 4. General Equations for the Total Amount of Renewable Generation in a State Under Various RPS

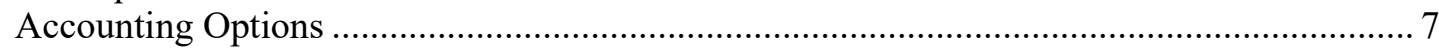

Table 5. General Equations for the Marginal Influence that an Additional kWh of Behind-the-meter PV has on the Total Renewable Generation Under Various Accounting Options 


\section{Introduction}

If a behind-the-meter solar photovoltaic (BTM PV) system is adopted, how does it influence the total amount of renewable electricity in the state in the long run (i.e., after the existence of the generator is reflected in the relevant utility's generation mix)? Would we expect the total amount of renewable generation to increase on a 1:1 basis with the BTM PV's generation? Or could it be something more, or something less?

In this paper we show that the answer can depend on two key elements of how BTM PV is accounted for within a state's Renewable Portfolio Standard (RPS). We find that, when the RPS is binding, under several of the accounting options BTM PV can increase the total amount of renewable generation in the state, whereas under a common RPS design, it can decrease total renewable generation in the state.

As a brief reminder, an RPS is a mandate requiring that utilities or load-serving entities obtain a certain percentage of the electricity they sell from renewable sources. The percentage usually increases over time; for example, Colorado's RPS was $20 \%$ in 2019 and is scheduled to increase to 30\% in 2020 (C.R.S. 40-2-124). Renewable energy is accounted for via the retirement of renewable energy certificates (RECs), which can come from utility-owned generators or be purchased from non-utilityowned generators.

RPSs have many design elements, but the core requirement is that a fraction of a utility's electric load must be served by eligible renewable generation: ${ }^{3}$

$$
\frac{\text { eligible renewable generation }}{\text { applicable electric load }}=\text { RPS goal }
$$

Looking first at the denominator of the equation, the applicable electric load is typically equivalent to the retail sales of the utility. It is important to recognize, however, that this is strictly an accounting term, and it can include or exclude certain types of electricity consumption per the discretion of the RPS designers. For example, for municipal utilities in California, electricity consumed by the city for its own municipal uses, such as water pumping, are excluded from the utility's applicable electric load. ${ }^{4}$ Despite the myriad possible exceptions for different types of load, for the purpose of this paper, we are only concerned with whether electric load served by generation from BTM PV is included in or excluded from the denominator. 5

\footnotetext{
${ }^{3}$ Because RPSs cover utilities with the RPS's state, we refer to the amount of renewable generation in a state in this paper. In certain states, however, utilities are allowed to purchase RECs from generators outside of their home state. This means that, while RECs are retired by in-state utilities, actual changes to renewable generation might occur outside of the RPS's state.

${ }^{4}$ For an example, see the Cerritos Electric Utility Procurement plan "Renewable Energy Resources Procurement Plan" (https://www.energy.ca.gov/portfolio/pous/cerritos/Cerritos RPS Plan.pdf).

${ }^{5}$ For example, consider a building that consumes $10 \mathrm{kWh}$ of electricity and generates $1 \mathrm{kWh}$ of electricity during a given period. For the purposes of RPS accounting, is the utility's applicable electric load $10 \mathrm{kWh}$ (the amount of electricity consumed) or $9 \mathrm{kWh}$ (the amount of electricity the utility sold to the building)?
} 
Next, looking at eligible renewable generation in the numerator of the equation, we recognize that different states have different rules for what generators are eligible to provide RECs for RPS compliance. These rules include which technologies are eligible, as well as other restrictions such as a generator's location. As with the denominator, there are various eligibility specifications, but for our purposes, we need to consider only one: whether RECs from BTM PV are eligible for RPS compliance.

The numerator and denominator provide two key choices about how BTM PV will be accounted for within the RPS:

1. Whether BTM PV RECs are considered eligible renewable generation for a utility's RPS compliance (influencing the numerator of the equation above)

2. Whether electricity consumption served by BTM PV counts toward the applicable electric load of a utility (influencing the denominator of the equation above). ${ }^{6}$

In practice, no state entirely excludes the use of BTM PV RECs for RPS compliance, but some states place caps or restrictions on their use. For example, California groups certain BTM PV systems into a category with other technologies whose total contribution through RECs is capped (Donalds 2017). Furthermore, the decision of whether to keep or sell RECs is typically up to the BTM PV system owner-even if an RPS allows the utility to purchase the RECs, the owner may choose to keep them. ${ }^{7}$

The question of whether load served by BTM PV generation counts toward the utility's applicable electric load is more complicated. In practice, load that is served directly by on-site BTM PV generation typically does not count toward the utility's electric load, because RPSs are typically defined in terms of a utility's retail sales, and PV generation consumed on-site never passes the utility's meter. Load that is served by exported PV generation, however, may or may not count, depending on how the generation is metered and how the RPS is defined. For example, in some service territories, exported electricity is tracked by reducing the nominal consumption by that customer, and therefore, none of the load ultimately served by the BTM PV generation counts toward the utility's applicable electric load, as any consumption by another customer is balanced against the nominally reduced load of the exporter. In contrast, other forms of accounting can track compensation for exported electricity as a financial credit instead of a kilowatt-hour $(\mathrm{kWh})$ credit, and thus any load served by the exported portion of the generation may count toward the utility's applicable load for the purpose of calculating RPS requirements. For the sake of simplicity, we refer to only "load served by BTM PV generation" throughout this paper, but it is important to understand that load served by exported BTM PV generation may be treated differently.

Beyond the two BTM PV accounting choices, there are numerous other elements of an RPS (e.g., which electricity providers are covered, the goal and time frame of the RPS, geographic restrictions on where RECs can be procured from, whether RECs need to be "bundled" with the purchase of the accompanying electricity, and many others). Though these other design elements are all important in

\footnotetext{
${ }^{6}$ Having load served by BTM PV generation count as applicable load would likely necessitate either separately metering the PV generation or estimating the PV generation using models or production factors, since a utility would need a measurement or estimate of how much BTM PV generation was consumed on-site.

${ }^{7}$ REC purchasing from BTM PV owners by utilities is often done through incentive programs.
} 
their own right, they are not relevant to this analysis, so we do not explore them here; for a list of additional literature on RPSs that look into some of these other design elements, see the appendix.

Lastly, before exploring the implications of the two BTM PV design choices in an RPS, two important caveats should be noted:

1. In all of the calculations in this paper, we implicitly assume that the RPS is binding (i.e., that the utility is in a situation where it would choose to procure less renewable generation if the RPS were not in place). We are not suggesting that RPSs are a cap or limit on renewable generation. The focus paper of this paper is on how BTM PV accounting within an RPS design can influence the amount of renewable energy generated if a utility is seeking to just meet their RPS obligation - if a utility chooses to procure more renewable energy than the minimum required, then the design of the RPS is irrelevant.

2. Relatedly, we assume that the binding RPS REC requirement directly and immediately determines how much renewable generation is consumed in the state; if the REC requirement is increased by $1 \mathrm{GWh} /$ year, for example, we assume that the amount of renewable generation consumed in the state increases by $1 \mathrm{GWh} /$ year. In practice, the response may not be direct nor immediate - it may take several years for a utility's generation mix to reflect a change in REC requirements. Furthermore, other RPS components, such as the ability to bank RECs between years or carve-outs and credit multipliers for certain technologies, could also complicate the relationship between REC requirements and renewable generation. We do not include these REC treatment variations in our analysis.

\section{How BTM PV Accounting in an RPS Can Affect Renewable Generation Requirements}

Having described the two relevant elements of RPS design in the previous section, we will now explore how those accounting options can influence the required amount of renewable generation using a theoretical example: We assume a state with 100 gigawatt-hours per year (GWh/year) of electricity consumption, an RPS of $30 \%$, and $5 \mathrm{GWh}$ /year of BTM PV generation, where all the BTM PV RECs are used for RPS compliance, if allowed.

For this hypothetical state, we assumed that $5 \%$ of the total energy consumption is provided by BTM PV. To put that into perspective, in 2018 BTM PV provided less than $2 \%$ of electricity in all states except California, Hawaii, New Jersey, and Maryland. California is estimated to receive approximately $5 \%$ of its electricity from BTM PV in $2019 .{ }^{8}$ NREL's 2018 Standard Scenarios report projects that BTM PV's contribution to the United States' total electricity supply could range from 1\% to 4\% in 2050 across the scenarios explored, with six states exceeding 10\% generation from BTM PV in the Low PV Cost scenario (Cole et al. 2018).

As a reminder, our two RPS elements are (1) whether BTM PV RECs are or are not used for RPS compliance and (2) whether load served by BTM PV generation counts or does not count toward the

\footnotetext{
${ }^{8}$ The estimate of energy penetration of BTM PV can be found in "California Energy Demand 2018-2030 Revised Baseline Forecast: Mid Demand Case” (https://efiling.energy.ca.gov/GetDocument.aspx?tn=226118\&DocumentContentId=56862).
} 
utility's applicable electric load. Those two elements give us four options for accounting for BTM PV in an RPS:

- Load served by BTM PV generation is included in the applicable load and BTM PV RECs are used for RPS compliance

- Load served by BTM PV generation is included in the applicable load and BTM PV RECs are not used for RPS compliance

- Load served by BTM PV generation is excluded in the applicable load and BTM PV RECs are used for RPS compliance

- Load served by BTM PV generation is excluded in the applicable load and BTM PV RECs are not used for RPS compliance

Table 1 shows the implications of these accounting details. Starting at the left column of the table, we see that the applicable electric load of our hypothetical state is either $100 \mathrm{GWh} /$ year or $95 \mathrm{GWh} /$ year, depending on whether the $5 \mathrm{GWh} /$ year of load covered by BTM PV is included. The effect of this is shown in the second column - the resulting RPS requirement is either $30 \mathrm{GWh} /$ year or $28.5 \mathrm{GWh} /$ year ( $30 \%$ of 100 and 95, respectively). Subtracting the amount of BTM PV RECs used for compliance (the $3^{\text {rd }}$ column), we derive the RECs required from sources other than BTM PV (the $4^{\text {th }}$ column). Adding those two values together gives us the total renewable generation under each accounting option $\left(5^{\text {th }}\right.$ column). ${ }^{9}$

This demonstrates the potential significance of these accounting details - in our hypothetical state with $100 \mathrm{GWh} /$ year of consumption and $5 \mathrm{GWh} /$ year of BTM PV, a nominal $30 \%$ RPS resulted in renewable generation ranging from $28.5 \mathrm{GWh} /$ year to $35 \mathrm{GWh} /$ year, depending on the accounting of BTM PV in the RPS. The magnitude of the deviation from the nominal RPS goal is linearly related to how much BTM PV is on the system - twice as much BTM PV yields twice the deviation for each accounting option.

\footnotetext{
${ }^{9}$ We assume that RECs are created at the point of generation, and that no adjustments are made to the RPS's REC requirement to account for losses. We explore the implications of this briefly later in the paper.
} 
Table 1. Renewable Energy Generation in a Hypothetical State Under Four Accounting Options for Behind-the-Meter PV in Renewable Portfolio Standards

\begin{tabular}{|c|c|c|c|c|c|c|}
\hline & $\begin{array}{l}\text { Applicable } \\
\text { Electric } \\
\text { Load } \\
\text { (GWh/year) }\end{array}$ & $\begin{array}{l}\text { RPS } \\
\text { Requirement } \\
\text { (GWh/year) }\end{array}$ & $\begin{array}{l}\text { BTM PV } \\
\text { RECs Used } \\
\text { for } \\
\text { Compliance } \\
\text { (GWh/year) }\end{array}$ & $\begin{array}{l}\text { RECs } \\
\text { Required } \\
\text { from } \\
\text { Sources } \\
\text { Other than } \\
\text { BTM PV } \\
\text { (GWh/year) }\end{array}$ & $\begin{array}{l}\text { Total } \\
\text { Renewable } \\
\text { Generation } \\
\text { (GWh/year) }\end{array}$ & $\begin{array}{l}\text { Difference } \\
\text { in } \\
\text { Renewable } \\
\text { Generation } \\
\text { from the } \\
\text { Baseline } \\
\text { (GWh/year) }\end{array}$ \\
\hline $\begin{array}{l}\text { Baseline (no } \\
\text { BTM PV) }\end{array}$ & 100 & 30 & 0 & 30 & 30 & - \\
\hline $\begin{array}{l}\text { Load served by BTM } \\
\text { PV generation is } \\
\text { included; BTM PV } \\
\text { RECs are used for } \\
\text { compliance }\end{array}$ & 100 & 30 & 5 & 25 & 30 & +0 \\
\hline $\begin{array}{l}\text { Load served by BTM } \\
\text { PV generation is } \\
\text { included; BTM PV } \\
\text { RECs are not used } \\
\text { for compliance }\end{array}$ & 100 & 30 & 0 & 30 & 35 & +5 \\
\hline $\begin{array}{l}\text { Load served by BTM } \\
\text { PV generation is } \\
\text { excluded; BTM PV } \\
\text { RECs are used for } \\
\text { compliance }\end{array}$ & 95 & 28.5 & 5 & 23.5 & 28.5 & -1.5 \\
\hline $\begin{array}{l}\text { Load served by BTM } \\
\text { PV generation is } \\
\text { excluded; BTM PV } \\
\text { RECs are not used } \\
\text { for compliance }\end{array}$ & 95 & 28.5 & 0 & 28.5 & 33.5 & +3.5 \\
\hline
\end{tabular}

As previously stated, we assumed that all BTM PV RECs are used for compliance, if allowed. If only a portion of them are used, either because of a cap on their usage or PV owners deciding to keep their RECs, then the result is a weighted mixture of the two relevant scenarios. For example, if load served by BTM PV is included in applicable load, but only half of the $5 \mathrm{GWh} /$ year of BTM RECs are used and half are not (the $2^{\text {nd }}$ and $3^{\text {rd }}$ row in Table 1 , respectively), then the total renewable generation is 32.5 $\mathrm{GWh} /$ year (a difference of $+2.5 \mathrm{GWh} /$ year from the baseline).

Table 2 summarizes the total renewable generation from Table 1 in the state, for the four accounting options. 
Table 2. Total Amount of Renewable Generation in a Hypothetical State Under Various RPS Accounting Options

\begin{tabular}{|l|c|c|}
\cline { 2 - 3 } \multicolumn{1}{c|}{} & $\begin{array}{l}\text { BTM PV RECs are used for RPS } \\
\text { compliance (GWh/year) }\end{array}$ & $\begin{array}{l}\text { BTM PV RECs are not used for } \\
\text { RPS compliance (GWh/year) }\end{array}$ \\
\hline $\begin{array}{l}\text { Load served by BTM PV } \\
\text { generation is included }\end{array}$ & 30.0 & 35.0 \\
\hline $\begin{array}{l}\text { Load served by BTM PV } \\
\text { generation is excluded }\end{array}$ & 28.5 & 33.5 \\
\hline
\end{tabular}

Assumptions: $100 \mathrm{GWh} /$ year of electricity consumption, $30 \% \mathrm{RPS}$, and $5 \mathrm{GWh} /$ year of BTM PV generation Without any BTM PV, renewable generation would be $30 \mathrm{GWh} / \mathrm{year}$.

In Table 3, we report the same results but cast them in terms of the effect that each kWh of BTM PV generation has on the total amount of renewable generation in the state, relative to how much there would be in absence of that $\mathrm{kWh}$.

Table 3. Marginal Influence that an additional kWh of Behind-the-meter PV has on the Total Renewable Generation Under Various Accounting Options, in a Hypothetical State with a $30 \%$ RPS

\begin{tabular}{|l|c|c|}
\cline { 2 - 3 } \multicolumn{1}{c|}{} & $\begin{array}{l}\text { BTM PV RECs are used for RPS } \\
\text { compliance }(\mathbf{k W h})\end{array}$ & $\begin{array}{l}\text { BTM PV RECs are not used for } \\
\text { RPS compliance (kWh) }\end{array}$ \\
\hline $\begin{array}{l}\text { Load served by BTM PV } \\
\text { generation is included }\end{array}$ & 0.0 & +1.0 \\
\hline $\begin{array}{l}\text { Load served by BTM PV } \\
\text { generation is excluded }\end{array}$ & -0.3 & +0.7 \\
\hline
\end{tabular}

Our analysis demonstrates that the mechanics of an RPS can significantly change the impact a BTM PV system has on the amount of renewable generation in a state. In the case that load served by BTM PV generation is excluded from the applicable load and BTM PV RECs can be used for compliance, the presence of BTM PV can actually decrease the total amount of renewable generation in the state, relative to how much there would be if there were no BTM PV. This is because the claim of renewable energy is transferred from a portion of load not covered by the RPS to the utility, which is covered. ${ }^{10}$

Conversely, with an RPS in which the BTM PV RECs are not used for RPS compliance and load served by BTM PV is included - a structure that no state currently implements - the total renewable generation increases on a one-to-one basis with the amount of BTM generation. This occurs because, under this accounting approach, even though the BTM PV owners would generate and retain RECs equal to $100 \%$ of the load that is served by their generation, the utility still remains responsible for retiring RECs to cover the RPS's fraction of that load. Consider $10 \mathrm{kWh}$ of load under a 30\% RPS: Without any BTM $\mathrm{PV}$, the utility must retire $3 \mathrm{kWh}$ of RECs. If that load is instead served by BTM PV and the owner keeps the $10 \mathrm{kWh}$ of RECs, the utility still must retire $3 \mathrm{kWh}$ of RECs - in total, there is now $13 \mathrm{kWh}$ of RECs, a one-to-one increase relative to where there was no BTM PV.

The other two accounting options fall between the previous two bounding cases. In the case that a BTM PV system's RECs are not used for RPS compliance, but the load served by BTM PV is excluded, the BTM PV generation also will increase the total amount of renewable generation in the state, but by less

\footnotetext{
${ }^{10}$ This is similar to the effects of purchasing unbundled RECs from another state that does not have a binding RPS
} 
than if the BTM PV generation is included. Under this accounting method, the BTM PV owners are covering the PV-served load with 100\% renewable energy, but also releasing the utility from being responsible for that load, which it would have otherwise had to cover a fraction of per the RPS goal. Lastly, if the BTM PV RECs are used for compliance, and the load served by the PV generation is included as applicable load, then the adoption of BTM PV does not change the total renewable generation in the state. The utility's REC obligation does not change with the adoption of the BTM PV, and it can use the BTM PV RECs to offset RECs it would have otherwise needed to generate or purchase from other sources.

\section{General Equations for Total Renewable Generation Under Different RPS Accounting Options}

As a generalization, it is helpful to recast Table 2 and Table 3 as equations instead of the examples of values we gave earlier. In Table 4 and Table 5, $\mathrm{C}$ is the total electricity consumption (including any consumption that was served by BTM PV whether or not it was counted as applicable load), G is generation from BTM PV (all generation, whether it was consumed on-site or exported), and R is the RPS goal expressed as a fraction of electricity consumption. Table 4 is analogous to Table 2; it provides formulas for the amount of renewable generation in a state. Table 5 is analogous to Table 3; it provides formulas for the impact of an additional unit of BTM PV generation on the total amount of renewable generation, relative to the amount of renewable generation expected with no BTM PV.

Table 4. General Equations for the Total Amount of Renewable Generation in a State Under Various RPS Accounting Options

\begin{tabular}{|l|c|c|}
\cline { 2 - 3 } \multicolumn{1}{c|}{} & $\begin{array}{l}\text { BTM PV RECs are used for } \\
\text { compliance }\end{array}$ & $\begin{array}{l}\text { BTM PV RECs are not used } \\
\text { for compliance }\end{array}$ \\
\hline $\begin{array}{l}\text { Load served by BTM PV } \\
\text { generation is included }\end{array}$ & $C^{*} R$ & $C^{*} R+G$ \\
\hline $\begin{array}{l}\text { Load served by BTM PV } \\
\text { generation is excluded }\end{array}$ & $(C-G)^{*} R$ & $(C-G)^{*} R+G$ \\
\hline
\end{tabular}

Without any BTM PV, renewable generation would equal $C^{*} R$

$\mathrm{C}=$ Total electricity consumption (includes BTM PV generation), G = BTM PV generation, and R = RPS goal

Table 5. General Equations for the Marginal Influence that an Additional kWh of Behind-the-meter PV has on the Total Renewable Generation Under Various Accounting Options

\begin{tabular}{|c|c|c|}
\hline & $\begin{array}{l}\text { BTM PV RECs are used for } \\
\text { compliance }\end{array}$ & $\begin{array}{l}\text { BTM PV RECs are not used } \\
\text { for compliance }\end{array}$ \\
\hline $\begin{array}{l}\text { Load served by BTM PV } \\
\text { generation is included }\end{array}$ & 0 & 1 \\
\hline $\begin{array}{l}\text { Load served by BTM PV } \\
\text { generation is excluded }\end{array}$ & $-R$ & $1-R$ \\
\hline
\end{tabular}

$\mathrm{R}=\mathrm{RPS}$ goal 


\section{Renewable Penetrations Under a Range of RPS Goals}

Our previous hypothetical example used a 30\% RPS and only reported absolute amounts of renewable generation, but we can learn more by performing calculations for RPS goals ranging from $0 \%$ to $100 \%$ and reporting the results in terms of renewable penetration. Importantly, however, there are two metrics we can use to describe renewable penetration, both of which can be meaningful. We can plot the amount of renewable generation as a percentage of total electricity consumption (including any consumption served by BTM PV generation, regardless of whether it is included or excluded in the RPS accounting), or as a percentage of total electricity generation.

The two terms differ by the losses incurred during transmission and distribution. Because RECs are created during generation, whereas RPSs are typically defined in terms of retail sales (consumption), the renewable generation as a percentage of total generation is lower than its percentage of consumption for a given RPS goal.

Consider, for example, a state that has a 100\% RPS goal, $100 \mathrm{GWh} /$ year of consumption, $5 \%$ losses, and no BTM PV. $100 \mathrm{GWh} /$ year of renewable generation would create enough RECs to satisfy the RPS requirement, but only $95 \mathrm{GWh} /$ year of that generation would actually reach the end users. Therefore, there would need to be an additional $5.26 \mathrm{GWh} /$ year of generation to meet all of the demand. If that generation was non-renewable, the renewable generation as a percentage of total generation would be $95 \%$, even though renewable generation would equal $100 \%$ of consumption. ${ }^{11}$

We plot the renewable generation for the four RPS accounting options as a percentage of consumption in Figure 1, and as a percentage of total electricity generation in Figure 2. We assume losses of 5.12\% (the annual average as estimated by the Environmental Protection Agency for the U.S. in 2016 [eGrid 2016]) for any non-BTM-PV generation for the calculations in Figure 2. Both calculations assume annual BTM PV generation equivalent to $10 \%$ of consumption-if there were more or less BTM PV, the trends shown below would be correspondingly more or less pronounced.

\footnotetext{
${ }^{11}$ Note that an RPS can be designed to counteract the effect of losses, by decreasing the compliance value of renewable generation or by increasing the compliance requirement by the amount of losses. In such a case, there would still be a difference between renewable penetration in terms of consumption or in terms of generation, but the relationship of both with the nominal RPS goal would change. A state with a 100\% RPS goal, for example, could have renewable penetration of $100 \%$ in terms of generation and in excess of $100 \%$ in consumption. As an example of how losses can be incorporated into an RPS, we can look to Hawaii. From their Public Utility Commission's annual report to the legislature: "Renewable electrical energy ... is based on recorded data of the energy generated ... adjusted downward for system losses" (State of Hawaii Public Utility Commission 2018, footnote 1 from Exhibit A).
} 
With this RPS design, renewable generation as a percentage of consumption would reach $100 \%$ with a nominal goal below $100 \%$

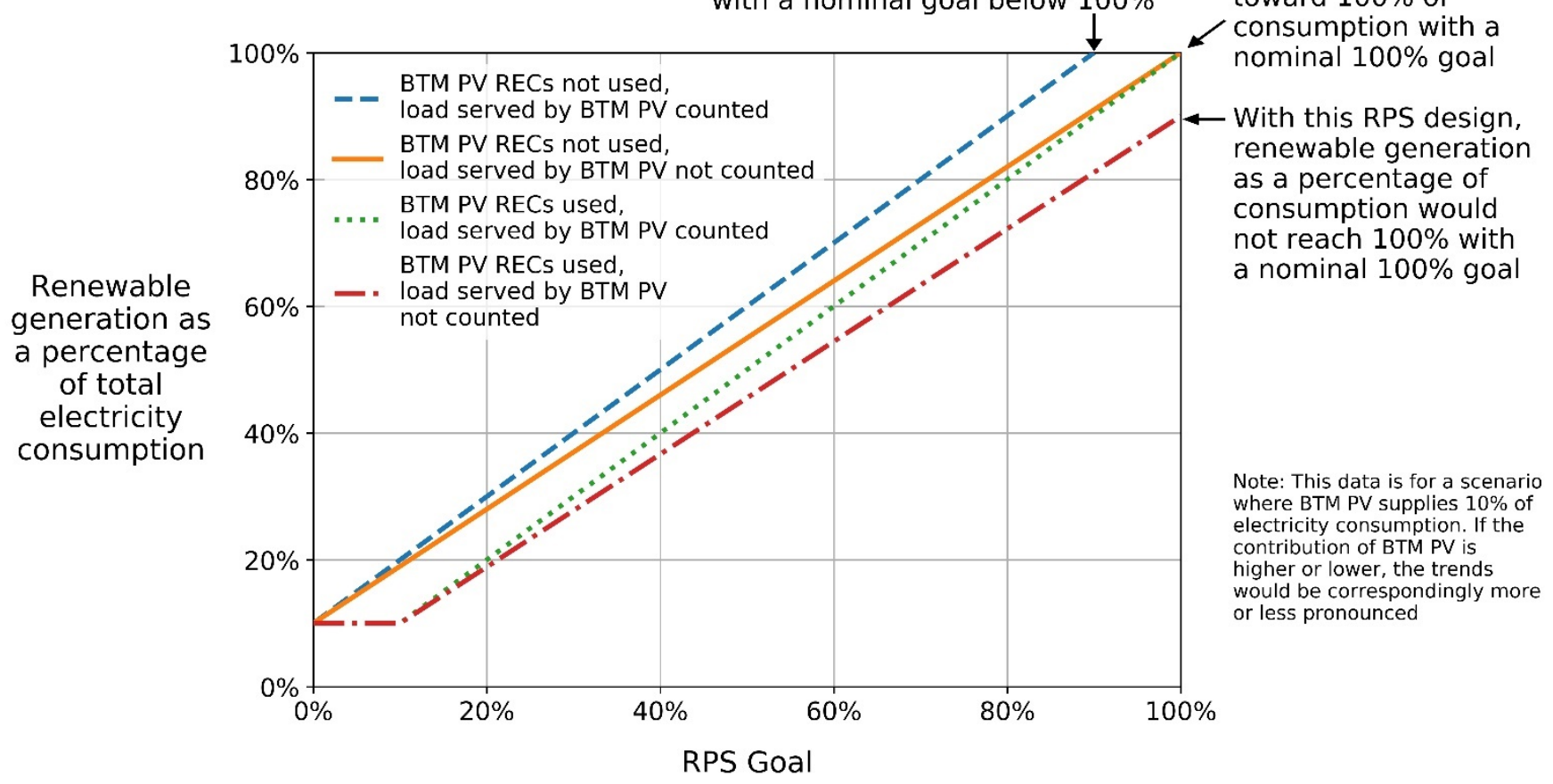

Figure 1. Renewable Generation as a Percentage of Total Electricity Consumption for a Range of RPS Goals, Under Four RPS Accounting Options

Assumptions: BTM PV supplies $10 \%$ of electricity consumption, all BTM PV RECs used for compliance if allowed, and RPS requirement is based on electricity consumption instead of generation.
With these two RPS designs, renewable generation converges toward $100 \%$ of consumption with a With this RPS design, ( consumption would not reach $100 \%$ with electricity consumption. If the contribution of BTM PV is or less pronounced would be correspondingly more 
The result of this RPS design is ambigious. When the effect of BTM PV outweighs the effect of losses (as shown here), 100\% renewable generation would occur with a nominal goal below $100 \%$. If losses outweigh BTM PV, a nominal $100 \%$ goal could have less than $100 \%$ renewable penetration

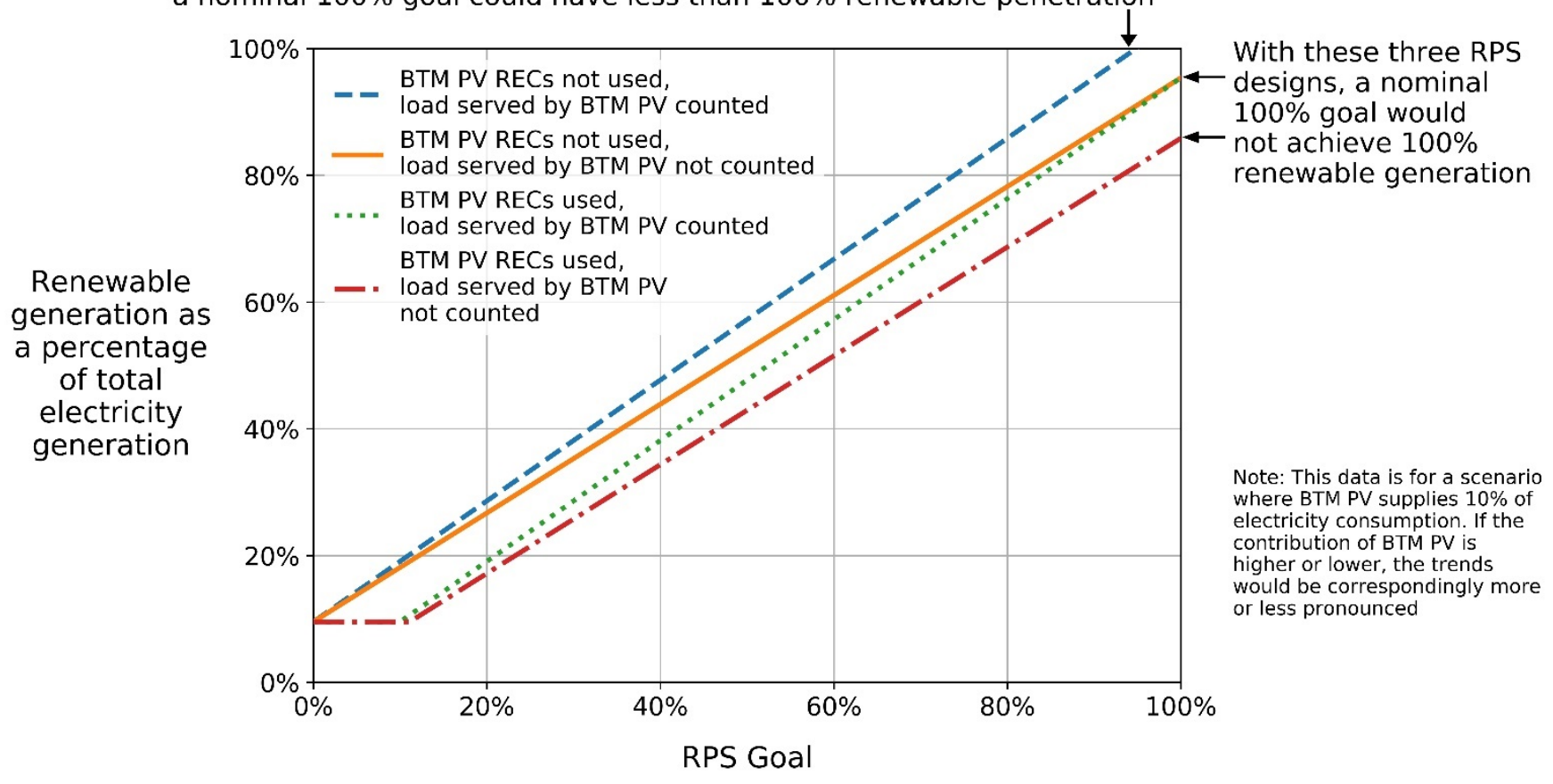

Figure 2: Renewable Generation as a Percentage of Total Electricity Generation for a Range of RPS Goals, Under Four RPS Accounting Options

Assumptions: BTM PV supplies $10 \%$ of electricity consumption, all BTM PV RECs used for compliance if allowed, RECs are created at the generation point, RPS requirement is based on electricity consumption instead of generation, and losses between generation and consumption are $5.12 \%$ for all non-BTM-PV generation.

Looking at the upper right-hand corner of both figures, we can see how much generation is actually required to be renewable for each RPS design under a nominal goal of $100 \%$. Figure 1 shows that under two of the accounting options (orange and green dotted lines), the renewable generation as a percentage of electricity consumption converges toward $100 \%$ as the RPS goal goes to $100 \%$ - but if we look at the same lines in Figure 2, we can see that both converge toward a value less than $100 \%$ in terms of total electricity generation. Defining renewable penetration in terms of consumption is how most RPS goals are defined, but examining the penetration in terms of generation shows us that a nominal goal of $100 \%$ can still allow non-renewable generation to be within a state's portfolio. This effect is not caused by BTM PV, however-it is caused by the losses during transmission and distribution of the renewable generation, as we explained earlier. ${ }^{12}$

For the accounting option where BTM PV RECs are used for compliance and load served by the generation is excluded (dashed red line), however, a nominal goal of $100 \%$ doesn't reach $100 \%$ renewable generation in terms of either consumption or generation. In Figure 1, this is only caused by BTM PV accounting. The load served by BTM PV generation is not covered by the RPS's requirement,

12 BTM PV actually slightly decreases the difference between the two metrics, since we assume its generation does not incur losses. Under the assumptions we've made here, the renewable percentage in terms of generation is $95.4 \%$ with BTM PV, whereas it would have been $94.9 \%$ without BTM PV. 
but the system owners could still sell their RECs to their utility, allowing the utility to meet its nominal $100 \%$ goal while still operating non-renewable generation sources. That effect is combined with the effect of losses to produce an even lower value in Figure 2.

Conversely, where BTM PV RECs are not used for compliance and load served by the generation is included (dashed blue line), 100\% renewable generation is reached before an RPS goal of 100\% is reached in terms of both consumption and generation - and therefore a goal of $100 \%$ would require the retirement of RECs that exceeded $100 \%$ of the electricity generation in the state unless the RPS design specifically addressed such a situation. Conceptually, this is because the utility is required to retire RECs to cover the load served by the BTM PV generation, but it cannot use the RECs from that generation to do so. Note that the effect of BTM PV accounting and the effect of losses are pushing in opposite directions under this accounting option-if there was less BTM PV, a goal of $100 \%$ may not require RECs in excess of $100 \%$ of renewable generation, since the loss effect could be greater than the effect of the BTM PV.

\section{Conclusions}

At the beginning of this paper we questioned how BTM PV might influence the total amount of renewable generation within its state, and posited that the answer depended on how BTM PV was accounted for within the state's RPS. In this paper we showed the mechanics of that interaction, and saw that the choices about accounting methods could have a noticeable influence; for a hypothetical example with $100 \mathrm{GWh} /$ year of load, $5 \mathrm{GWh} /$ year of BTM PV generation, and a 30\% RPS, the total amount of renewable generation in the state varied from $28.5 \mathrm{GWh} /$ year to $35 \mathrm{GWh} /$ year across the different RPS accounting options we examined.

The results were also cast in terms of how an incremental BTM PV system could impact the total amount of renewable generation in the state. Under one RPS design, the increase in renewable generation would equate 1:1 with the amount of generation from the BTM PV system-however, no state currently implements an RPS in this form. Under a more common RPS design, in which BTM PV system owners can sell their RECs to their utility for compliance, but any load served by the BTM PV generation does not count as load within the RPS accounting, the presence of BTM PV can reduce the total number of required RECs and can therefore decrease the total amount of renewable generation in the state, relative to how much there would have been without the BTM PV.

Lastly, we examined the actual renewable penetration - in terms of both the percentage of consumption and the percentage of generation - under a range of RPS goals, up to $100 \%$. When evaluating penetration in terms of consumption, we saw that although two of the four RPS accounting options produced the intuitive result of a nominal 100\% RPS goal resulting in 100\% renewable generation, we also saw how other RPS accounting options did not have that result — one option could result in less than $100 \%$ renewable generation within the state, while another could require the retirement of RECs in excess of $100 \%$ of the state's electricity generation. When RPS compliance is defined in terms of retail sales (consumption) but creating RECs is based on generation - as we assumed in our calculations- the effect of transmission and distribution losses is that the renewable penetration in terms of generation is lower than the penetration in terms of consumption. 


\section{References}

Barbose, Galen. (2018). U.S. Renewable Portfolio Standards: 2018 Annual Status Report. Berkeley, CA: Lawrence Berkeley National Laboratory. http://etapublications.lbl.gov/sites/default/files/2018_annual_rps_summary_report.pdf

Cole, Wesley, Will Frazier, Paul Donohoo-Vallett, Trieu Mai, and Paritosh Das. (2018). 2018 Standard Scenarios Report: A U.S. Electricity Sector Outlook. NREL/TP-6A20-71913. Golden, CO: National Renewable Energy Laboratory. https://doi.org/10.2172/1481848.

CRS. (2016). Colorado Revised Statutes 2016: Title 40: Utilities: Public Utilities: General and Administrative. https://leg.colorado.gov/sites/default/files/images/olls/crs2016-title-40.pdf.

Donalds, Samantha. (2017). Distributed Generation in State Renewable Portfolio Standards. Prepared for The RPS Collaborative. Montpelier, VT: Clean Energy States Alliance. https://www.cesa.org/assets/2017-Files/DG-RPS.pdf

EPA. (2018). Emissions \& Generation Resource Integrated Database (eGRID) with 2016 data. https://www.epa.gov/energy/emissions-generation-resource-integrated-database-egrid

Mai, Trieu, Ryan Wiser, Galen Barbose, Lori Bird, Jenny Heeter, David Keyser, Venkat Krishnan, Jordan Macknick, and Dev Millstein. (2016). A Prospective Analysis of the Costs, Benefits, and Impacts of U.S. Renewable Portfolio Standards. Berkeley, CA: Lawrence Berkeley National Laboratory. NREL/TP-6A20-67455, LBNL-1006962. https://doi.org/10.2172/1344104.

State of Hawaii Public Utilities Commission. (2018). Report to the 2019 Legislature on Hawaii's Renewable Portfolio Standards. https://puc.hawaii.gov/wp-content/uploads/2018/12/RPS-2018Legislative-Report FINAL.pdf

Wiser, Ryan, Galen Barbose, Jenny Heeter, Trieu Mai, Lori Bird, Mark Bolinger, Alberta Carpenter, Garvin Heath, David Keyser, Jordan Macknick, Andrew Mills, and Dev Millstein. (2016). A retrospective analysis of the benefits and impacts of US renewable portfolio standards. Berkeley, CA: Lawrence Berkeley National Laboratory. NREL/TP-6A20-65005. https://emp.lbl.gov/sites/all/files/lbnl1003961.pdf 


\section{Appendix: RPS Literature and Resources}

The following are resources for understanding RPSs beyond the limited scope of this report:

- Lawrence Berkeley National Laboratory (LBNL) has published annual RPS reviews (e.g., Barbose 2018); see "Renewables Portfolio Standards Resources ," LBNL, https://emp.lbl.gov/projects/renewables-portfolio.

- NREL and LBNL have produced both prospective (Mai et al. 2016) and retrospective (Wiser et al. 2016) analyses of the costs, benefits, and impacts of RPSs.

- The Clean Energy States Alliance (CESA) has characterized how distributed generation is included in RPSs (Donalds 2017), and it provides RPS design guides; see " RPS Publications," CESA, https://www.cesa.org/projects/renewable-portfolio-standards/rps-publications/). CESA also organizes the RPS Collaborative, which is meant to connect various stakeholders involved with RPS; see "Renewable Portfolio Standards and the RPS Collaborative," CESA, https://cesa.org/projects/renewable-portfolio-standards/.

- The Database of State Incentives for Renewables \& Efficiency (DSIRE), has tracked state RPS policies; see "Database of State Incentives for Renewables \& Efficiency" www.dsireusa.org. 
